\title{
Part-set cuing inhibition in category-instance and reason generation
}

\author{
STEVEN A. SLOMAN \\ Stanford University, Stanford, California
}

(Gordon H. Bower, Sponsor)

\begin{abstract}
Two experiments are reported in which the existence of part-set cuing inhibition was confirmed with tasks that involved the generation of items from general knowledge. In Experiment 1, larger part-set inhibition effects were observed in a task of category-instance generation than in an episodic task of category-instance cued recall. In Experiment 2, the number of reasons generated concerning a hypothesis was reduced through the presentation of example reasons. The presence of the example reasons did not affect likelihood judgments concerning the issue; however, judgments were higher for one of two issues when pro rather than con reasons were generated.
\end{abstract}

In demonstrations of part-set cuing inhibition, subjects cued with part of a set of to-be-generated items generate fewer of the remaining items than do subjects who are not cued. The generality of the phenomenon has been documented by reports of part-set inhibition in many disparate domains (Peynircioğlu, 1987; Roediger \& Neely, 1982). Investigators have paid particular attention to the special case of episodic part-list cuing inhibition, in which presenting a subset of studied list words at the time of recall of a list often reduces the number of noncue words recalled (see Nickerson, 1984, for a review).

Two attempts to extend the generality of the phenomenon in memory tasks that do not depend on retrieval of particular episodes are reported here. In Experiment 1, the amount of part-set inhibition observed in an episodic task of category-instance cued recall was compared with the amount observed in a roughly comparable semantic task of category-instance generation. In Experiment 2, the effect of part-set cues on the generation of reasons relevant to some hypothesis was examined, along with the possibility of additional effects of cues on likelihood judgments.

\section{EXPERIMENT 1}

A task was used that had semantic and episodic versions with comparable responses-generating category instances. The episodic version consisted of presenting the same words that subjects were expected to generate in the semantic case, and then testing recall by cuing with category names. Inhibition in category-instance generation has already been reported by Watkins and Allender

This research was supported by Grant $\mathrm{MH}-15157-14$ from the National Institute of Mental Health and Air Force Grant AFOSR-87-0282 to Gordon H. Bower. Experiment 2 was done with the assistance of Eric Brandon. Steven Sloman is now at the Department of Psychology, University of Michigan, 330 Packard Rd., Ann Arbor, MI 48104-2994.
(1987), who found a decrease in the number of words generated from semantic and graphemic categories when other instances from the same category were being heard.

\section{Method}

A $2 \times 2$ design was used; type of task (semantic or episodic), tested between-subjects, was crossed with the presence or absence of part-list cues (within-subjects). Six categories, each with 10 words of frequency greater than 10, were chosen from the Battig and Montague (1969) norms. The subjects were introductory psychology students at Stanford University. The episodic group $(N=28)$ listened to a tape of these 60 words, blocked by category (but without category names), for $4 \mathrm{sec}$ per word. After approximately $8 \mathrm{~min}$ spent completing an unrelated questionnaire, their recall was tested. The 24 semantic memory subjects started the experiment by completing the questionnaire and then began the category-instance generation task.

The design of the memory-testing phase was identical for the two groups. Three of the six categories were tested without part-set cues; only the names of the categories were used to cue retrieval or instance generation. The other three categories were tested with part-set cues. For these categories, five randomly selected instances appeared below the category name. These five words were identical each time the category was tested in the part-set cuing condition. Categories were presented in a counterbalanced order, so that each appeared an equal number of times in the uncued and part-list cued conditions and these conditions, in turn, appeared equally often as the first or second conditions.

The episodic subjects were told to write down as many words as they could from the specified category from the presentation phase. They were told that sometimes they would see some of the words that had been presented under the category name and that they need not write these words down. The semantic subjects were told to write down as many instances as they could from the appropriate category in the limited amount of time that they would be given, and that sometimes there would be some examples to help them along. The subjects were allowed up to $50 \mathrm{sec}$ for recall or generation from each category, which was about as much time as they needed.

\section{Results and Discussion}

Performance was scored by counting only items never given as cues. Thus the maximum recall score was 5 in the episodic case. Instances were counted as correct in the semantic task if they had a Battig-Montague frequency of greater than 10 and were not part-list cues. The mean 
Table 1

Mean Number of Instances Per Category Recalled or Generated (with Standard Errors) as a Function of Type of Task and Presence (PLC) or Absence (Control) of Part-List Cues

\begin{tabular}{lccccc}
\hline & \multicolumn{4}{c}{ Cue Condition } \\
\cline { 2 - 3 } \cline { 5 - 6 } & \multicolumn{2}{c}{ PLC } & & \multicolumn{2}{c}{ Control } \\
\cline { 2 - 3 } \cline { 5 - 6 } & $M$ & $S E$ & & $M$ & $S E$ \\
\hline Semantic & 4.17 & .37 & & 5.00 & .30 \\
Episodic & 1.96 & .15 & & 2.13 & .18 \\
\hline
\end{tabular}

number of instances written down per category for each condition are shown in Table 1 , along with standard errors. Not only was there part-list inhibition with the semantic task, but there was more inhibition than there was with the episodic task. Although the number of category instances generated was significantly lower with the part-list cues than it was in the control condition $[t(23)=2.85, p<.01]$, the corresponding difference, though in the same direction, was not significant in the episodic category cued recall task despite the larger number of subjects $(t<1)$. The large amount of inhibition found with the semantic generation task provides further evidence of the generality of part-set cuing inhibition.

The absence of inhibition in episodic recall might have been due to facilitation from the cues. Cues might have permitted access to categories that would otherwise not have been retrieved. To investigate this possibility, we examined conditional proportions by calculating the mean recall in categories for which at least one item had been recalled. Still no part-list inhibition obtained. The tiny difference found in the direction of part-list inhibition in episodic recall is actually comparable in magnitude to differences found by other experimenters using categorized lists (Mueller \& Watkins, 1977; Roediger, 1973; Rundus, 1973; Slamecka, 1968). Other experiments, like the present one, have not yielded any statistically significant inhibition (Slamecka, 1972) either.

\section{EXPERIMENT 2}

In Experiment 2, the effect of part-set cuing on the generation of reasons was examined. The subjects generated reasons in support of one side of an issue in the presence of one or two reasons consistent with that side or with no example reasons present. Thus, reasons served as both part-set cues and items to be generated. For purposes not directly relevant here, the reasons given to the subjects were either weak or strong. To gauge the influence of the cues and of any inhibition observed on their attitudes, the subjects were asked for a judgment of the likelihood of the prediction associated with the issue after having generated reasons.

\section{Method}

Reasons were generated, and likelihood estimates were collected, for two issues: a political one, whether the Bush Administration would continue the Star Wars program (the experiment was performed immediately after Bush's election), and a more personal one, whether or not the subject would go to graduate school. The subjects were asked to generate as many reasons as they could in one of six conditions. They either generated pro reasons (why the Bush Administration would continue with Star Wars or why they would go to graduate school) or con reasons. They generated these reasons in either the presence or the absence of other reasons given as examples (one reason was given for the Star Wars issue and two for the graduate school issue). When reasons were given, in some cases they were weak; for example, a weak pro Star Wars reason was that "it would be a bad idea for President Bush to alienate defense industry executives," and the con graduate school weak reasons were, "You won't be able to relate to ordinary people any more. You are likely to end up sharing a tiny office." Sometimes the reasons were strong: For example, a strong pro reason was that "Star Wars is too important a bargaining chip in arms control negotiations with the Soviets to give up." and the strong con graduate school reasons were that "the extra income from a graduate degree almost never outweighs the income you could have earned during the same years. The advantages of a graduate degree almost never outweigh the work experience you could have accumulated during the same years." Next, the subjects provided a likelihood estimate relevant to the issue by circling 1 of 11 evenly spaced percentage figures between and including 0 and 100. For instance, for the Star Wars issue, they estimated the likelihood that the Bush Administration would continue the Star Wars program.

Between 23 and 28 Stanford undergraduates were tested in each condition of each issue. Each subject was tested in different conditions (selected randomly) of both issues. The subjects were given two-page questionnaires (one issue per page), and they worked at their own pace.

\section{Results and Discussion}

A reason was counted if, in the experimenters' opinion, any subject might have felt free to write it down, regardless of the reasons given as cues. To ensure the reliability of the tally, two experimenters counted the reasons generated by each subject. The interjudge correlations were quite high, .92 for Star Wars (SDI) and .79 for graduate school. Therefore, I report the mean number of these noncue reasons (averaged over the judges), which are shown for each condition of each story in Table 2 . The results would not be substantially altered if we considered each judge's counts separately. Standard errors were all between .25 and .43. The differences were examined using contrasts separately for the two issues. For both issues, more reasons were generated when no cues were provided than when some were [for graduate school, $t(145)=3.25, p<.001$, and for SDI, $t(152)=2.66 ; p<.01]$. Although more reasons were

Table 2

Mean Number of Generated Reasons not Given as Cues in Experiment 2 for Each Cue Condition and Type of Reason (Pro or Con)

\begin{tabular}{lccc}
\hline & \multicolumn{3}{c}{ Cue Condition } \\
\cline { 2 - 4 } Type of & No & Weak & Strong \\
Reason & Cue Reason & Cue Reasons & Cue Reasons \\
\hline
\end{tabular}

\begin{tabular}{lrrr} 
Pro & 4.26 & 3.00 & 3.70 \\
Con & 4.40 & 4.25 & 2.65 \\
$M$ & 4.33 & 3.66 & 3.17 \\
& \multicolumn{3}{c}{ Star Wars } \\
Pro & 3.96 & 3.33 & 2.92 \\
Con & 3.70 & 3.04 & 3.19 \\
$M$ & 3.83 & 3.34 & 3.05 \\
\hline
\end{tabular}


Table 3

Mean Likelihood Estimates for Two Issues in Experiment 2 for Each Cuing Condition and Each Type of Reason Generated (Pro or Con)

\begin{tabular}{|c|c|c|c|c|}
\hline \multirow[b]{2}{*}{$\begin{array}{l}\text { Type of } \\
\text { Reason }\end{array}$} & \multicolumn{3}{|c|}{ Cue Condition } & \multirow[b]{2}{*}{$M$} \\
\hline & $\begin{array}{c}\text { No } \\
\text { Cue Reason }\end{array}$ & $\begin{array}{c}\text { Weak } \\
\text { Cue Reasons } \\
\end{array}$ & $\begin{array}{c}\text { Strong } \\
\text { Cue Reasons } \\
\end{array}$ & \\
\hline \multicolumn{5}{|c|}{ Graduate School } \\
\hline $\begin{array}{l}\text { Pro } \\
\text { Con }\end{array}$ & $\begin{array}{l}78.7 \\
77.9\end{array}$ & $\begin{array}{l}77.4 \\
75.4\end{array}$ & $\begin{array}{l}77.2 \\
71.7\end{array}$ & $\begin{array}{l}77.7 \\
75.0\end{array}$ \\
\hline \multicolumn{5}{|c|}{ Star Wars } \\
\hline $\begin{array}{l}\text { Pro } \\
\text { Con }\end{array}$ & $\begin{array}{l}78.2 \\
61.4\end{array}$ & $\begin{array}{l}70.2 \\
66.0\end{array}$ & $\begin{array}{l}71.9 \\
61.9\end{array}$ & $\begin{array}{l}73.6 \\
63.1\end{array}$ \\
\hline
\end{tabular}

generated overall after weak cues than after strong cues, this difference was not significant for either graduate school $[t(145)=1.54$, n.s. $]$ or SDI $[t(152)=1.02$, n.s. $]$. Moreover, more reasons were generated in the strong condition for two out of the four comparisons. Part-set cuing inhibition obtained in reason generation in that the presence of reason cues inhibited the generation of other reasons of the same type.

Despite the effect of cuing condition on reason generation, it had no effect on likelihood estimates, which are shown in Table 3. Standard errors were between 2.8 and 3.3. The subjects in all conditions of the graduate school issue gave approximately the same likelihood estimates. No analyses yielded significant differences. Apparently these students had a good idea of whether they would be going to graduate school or not, and to ask them for their reasons why or why not had little influence on a presumably rather well-ingrained belief. For the SDI issue, again no overall difference between the three cue conditions obtained. Except for a slight increase in confidence judgments after generating pro reasons with no cues present, the presence of cues had little effect. However, in this case, subjects who generated pro reasons gave higher likelihood estimates than did the subjects who generated con reasons. A two-way analysis of variance with cue type and pro versus con reasons as factors showed a significant effect of pro versus con only $[F(1,149)=10.18$, $p<.01]$. The differential effect of generating pro and con reasons on likelihood judgments found using the Star Wars issue is consistent with findings of Koriat, Lichtenstein, and Fischhoff (1980).

The correlation between the number of noncue reasons that subjects generated and their likelihood estimates was low but significant for pro-reason subjects but negligible for con-reason subjects. For graduate school, $r=.145$ $(p<.05)$ when pro reasons were generated, and $r=$ .012 (n.s.) when reasons were con. For SDI, $r=.148$ $(p<.05)$ for pro reason subjects, and $r=.000$ for con. These low correlations are consistent with the lack of effect that the various cue conditions had on likelihood judgments.

\section{GENERAL DISCUSSION}

Part-set cuing inhibition is apparently as easy to find in tasks that involve generation from semantic memory as it is to find in tasks of episodic recall. To the extent that the amounts of inhibition observed in the two cases are sensitive to similar experimental variables, we may feel compelled to treat them similarly theoretically. Sloman, Bower, and Rohrer (1990) provide evidence that an incongruency principle concerning the relation between part-set cues and to-be-generated items helps to predict inhibition in episodic recall; the role of congruency in semantic memory inhibition is as yet unknown.

\section{REFERENCES}

Battig, W. F., \& Montague, W. E. (1969). Category norms for verbal items in 56 categories: A replication and extension of the Connecticut category norms. Journal of Experimental Psychology Monographs, 80(3, Pt. 2).

Koriat, A., Lichtenstein, S., \& Fischhoff, B. (1980). Reasons for confidence. Journal of Experimental Psychology: Human Learning \& Memory, 6, 107-118.

Mueller, C. W., \& Watkins, M. J. (1977). Inhibition from part-set cuing: A cue-overload interpretation. Journal of Verbal Learning \& Verbal Behavior, 16, 699-709.

NiCKerson, R. S. (1984). Retrieval inhibition from part-set cuing: A persisting enigma in memory research. Memory \& Cognition, 12, 531-552.

PeynircioĞlu, Z. F. (1987). On the generality of the part-set cuing effect: Evidence from nonmemory tasks. Journal of Experimental Psychology: Learning, Memory, \& Cognition, 13, 437-442.

ROEDIGER, H. L., III. (1973). Inhibition in recall from cueing with recall targets. Journal of Verbal Learning \& Verbal Behavior, 12, 644-657.

Roediger, H. L., III, \& NeELy, J. H. (1982). Retrieval blocks in episodic and semantic memory. Canadian Journal of Psychology, 36, 213-242.

Rundus, D. (1973). Negative effects of using list items as recall cues. Journal of Verbal Learning \& Verbal Behavior, 12, 43-50.

SLAMECKA, N. J. (1968). An examination of trace storage in free recall. Journal of Experimental Psychology, 76, 504-513.

SLAmECKA, N. J. (1972). The question of associative growth in the learning of categorized materials. Journal of Verbal Learning \& Verbal Behavior, 11, 324-332.

Sloman, S. A., Bower, G. H., \& Rohrer, D. (1990). Congruency effects in part-list cuing inhibition. Manuscript submitted for publication.

WatkINS, M. J., \& Allender, L. E. (1987). Inhibiting word generation with word presentations. Journal of Experimental Psychology: Learning, Memory, \& Cognition, 13, 564-568.

(Manuscript received September 4, 1990.) 